\title{
PENINGKATAN EFEKTIFITAS DAN EFISIENSI USAHA PERIKANAN TANGKAP LAUT SKALA KECIL MELALUI FASILITASI PETA PERKIRAAN 'FISHING GROUND'
}

\author{
Sonny Koeshendrajana, Tenny Apriliani dan Maulana Firdaus \\ Balai Besar Penelitian Sosial Ekonomi Kelautan dan Perikanan \\ JI. KS. Tubun Petamburan VI Jakarta 10260 \\ Telp. (021) 53650162, Fax. (021)53650159 \\ Email:sonny_koes@yahoo.com
}

Diterima 7 Mei 2012 - Disetujui 20 Juni 2012

\begin{abstract}
ABSTRAK
Usaha perikanan tangkap laut skala kecil mendominasi struktur perikanan Indonesia, mencakup > $90 \%$ dari struktur perikanan tangkap yang ada di Indonesia. Permasalahan utama dalam pengembangan usaha perikanan pada kelompok ini adalah keterbatasan aset dan permodalan serta sifat musiman dan resiko ketidak pastian sebagai akibat keterbatasan kapasitas yang dimiliki. Hal ini diperparah oleh minimnya keberpihakan penentu kebijakan pada kelompok usaha tersebut. Tulisan ini merupakan bagian dari penelitian Panel Kelautan dan Perikanan Nasional (PANELKANAS) yang bertujuan menyediakan database yang akurat di tingkat mikro yang mampu merepresentasikan kinerja pembangunan sektor kelautan dan perikanan. Secara spesifik penulisan artikel ini bertujuan untuk merumuskan rekomendasi kebijakan peningkatan efektivitas dan efisiensi pengelolaan perikanan tangkap laut skala kecil melalui fasilitasi peta perkiraan 'fishing ground'. Data primer dan sekunder digunakan dalam penelitian ini. Data primer diperoleh melalui survei monitoring terhadap 30-40 contoh responden rumah tangga nelayan terpilih dengan menggunakan bantuan kuesioner terstruktur di lokasi Sibolga, Sampang dan Bitung; sedangkan data sekunder diperoleh dari laporan tahunan berbagai institusi terkait maupun hasil-hasil penelitian terdahulu. Analisis statistik deskriptif digunakan dalam penelitian ini, sedangkan penyajian dilakukan secara deskriptif eksploratif dengan bantuan teknik tabulasi silang. Hasil kajian memberikan ilustrasi dinamika musim penangkapan ikan di laut di lokasi terpilih, dinamika penguasaan aset dan investasi berdasarkan tipologi penangkapan, dinamika struktur biaya dan pendapatan serta rumusan rekomendasi kebijakan peningkatanan efektivitas dan efisiensi pengelolaan perikanan tangkap laut skala kecil melalui fasilitasi peta perkiraan 'fishing ground'.
\end{abstract}

Kata Kunci: PANELKANAS, nelayan skala kecil, perikanan tangkap, peta perkiraan 'fishing ground'.

\section{Abstract: Improving Effectivity and Effienciency of Small-Scale Fisheries Business Through Facilitating the Estimated Fishing Ground Map. By: Sonny Koeshendrajana, Tenny Apriliani and Maulana Firdaus.}

Small-scale fisheries business dominated the structure of Indonesian fisheries covering more than 90\% of the structure of marine fisheries in Indonesia. Primary problems in the development of the sector were limited assets and capital as well as the seasonal nature and the uncertainties as a result of lack of capacity in managing the business. This situation compounded by lack of decision makers support to small scale fisheries. This paper is a part of Research Panel of the National Marine and Fisheries (PANELKANAS) which aims to provide an accurate data base at micro level by which are able to represent performance of the development of marine and fisheries sector. Specifically, this article aims to formulate policy recommendations to improving the effectiveness and efficiency marine capture fisheries management through facilitating an estimated 'fishing ground' map for small-scale fishers. Primary and secondary data 
were used in this study. Primary data were obtained through monitoring survey of 30-40 samples of selected fisher households by using a structured questionnaire at the Sibolga, Sampang and Bitung regencies, while secondary data were obtained from various institutions related to the annual report and the results of previous studies. A Descriptive statistics analysis was used in this study while the report was presented descriptive-exploratory by using cross tabulation techniques. Results of the study illustrate the dynamics of fishing season at selected locations, dynamic of control assets and investments based on the marine capture fisheries typology, dynamics of cost and revenue structure and formulation policy recommendations to improving the effectiveness and efficiency of marine capture fisheries management through the facilitation of small-scale map of the estimated 'fishing ground'.

Keywords: PANELKANAS, small scale fisheries, captured fisheries, estimated of fishing ground map

\section{PENDAHULUAN}

Pelaku usaha skala kecil relatif kurang mendapat perhatian dalam upaya peningkatan efektifitas dan efisiensi pengelolaan usaha perikanan tangkap yang dilakukan. Unit armada penangkapan yang dijalankan oleh kelompok usaha tersebut adalah perahu bermotor dengan ukuran < 5 GT dengan menggunakan alat tangkap tradisional dan jangkauan penangkapan yang terbatas; bahkan di beberapa tempat dijumpai akses mereka terhadap faktor produksi utama (BBM) sangat terbatas. Hasil kajian berbagai peneliti (Bahri, 1995; Wijaya et al, 2010) mengungkapkan bahwa permasalahan utama yang dihadapi oleh para pelaku usaha perikanan tangkap skala kecil adalah keterbatasan aset dan permodalan, sifat musiman dan faktor resiko ketidak pastian sebagai akibat keterbatasan data dan informasi; sementara itu, Dwiponggo et al, (1988), mengungkapkan bahwa 90\% perikanan tangkap di Indonesia baru berupa perikanan skala kecil, sedangkan sisanya adalah perikanan maju atau komersil. Bahkan untuk kondisi sekarang, menurut Dahuri (2003), perikanan skala kecil di Indonesia mencapai $98,2 \%$ dari seluruh pelaku usaha yang ada pada usaha perikanan tangkap.

Hasil kajian Komisi Nasional Pengkajian Stok Ikan (KOMNAS KAJISKAN) mengindikasikan bahwa di banyak tempat telah terjadi 'overfishing', hal ini berdampak semakin bertambah lama bagi nelayan untuk mencapai daerah penangkapan ikan (fishing ground) yang diinginkan. Keadaan seperti ini terjadi pada kelompok nelayan skala kecil yang di amati dan secara tidak langsung mengindikasikan bahwa mereka merupakan kelompok yang relatif lemah kapasitasnya baik dalam hal mendapatkan atau menerima informasi maupun meng-akses-nya. Terkait dengan hal tersebut, penyediaan peta perkiraan 'fishing ground' sebetulnya telah menjadi salah satu kebijakan dan program Kementerian Kelautan dan Perikanan (KKP) dalam upaya peningkatan efektifitas dan efisiensi pengelolaan usaha perikanan tangkap; tetapi, sampai saat ini, distribusi peta perkiraan yang telah diterbitkan masih terbatas di pelabuhan-pelabuhan perikanan besar dan Dinas Perikanan setempat (BROK, 2008). Daerah-daerah yang tidak memiliki pelabuhan perikanan besar dan terletak pada wilayah yang relatif terisolasi umumnya kurang/tidak terjangkau target sasaran hingga pelaku usaha skala kecil.

Penyediaan peta perkiraan 'fishing ground' dinilai dapat menekan biaya operasional penangkapan ikan, terutama dalam konteks mencari daerah-daerah potensial yang terdapat stok atau populasi ikan yang menjadi target penangkapan (BROK, 2008). Oleh karena itu, dipandang penting mengupayakan peningkatan efektifitas dan efisiensi pengelolaan usaha perikanan tangkap melalui fasilitasi peta perkiraan seperti dimaksudkan di atas sesuai dengan kapasitas pelaku usaha tersebut. 


\section{METODOLOGI}

\section{Lokasi dan Waktu Penelitian}

Penelitian ini dilakukan di Kelurahan Batu Lubang Kota Bitung, Provinsi Sulawesi Utara; Desa Ketapang Barat, Kabupaten Sampang, Provinsi Jawa Timur dan Desa Aek Habil, Kabupaten Sibolga, Provinsi Sumatera Utara. Penelitian dilaksanakan pada tahun 2010 dan 2011.

\section{Metode Pengumpulan Data}

Jenis data yang digunakan dalam penelitian ini adalah data primer dan sekunder. Data primer diperoleh melalui survei monitoring berdasarkan hasil wawancara dengan responden terpilih berkisar 30 sampai dengan 40 responden pada masing-masing lokasi yang dipilih secara acak terstratifikasi (stratified random sampling) dengan menggunakan alat bantu kuesioner. Data sekunder diperoleh dari berbagai penelitian terdahulu terkait tujuan penelitian dan laporan tahunan serta statistik dari dinas terkait, seperti Dinas Kelautan dan Perikanan Kabupaten dan Badan Pusat Statistik.

Data primer yang dikumpulkan mencakup karakteristik responden yang meliputi umur, tingkat pendidikan dan jumlah anggota keluarga. Didamping itu, dikumpulkan juga informasi yang terkait dengan aktifitas penangkapan ikan yang meliputi penguasaan aset, musim penangkapan dan pembiayaan usaha penangkapan ikan pada masing-masing lokasi.

\section{Metode Analisis Data}

Analisis data yang akan dilakukan adalah analisis deskriptif dan diinterpretasikan secara tabulasi silang dengan uraian deskriptif yang menggambarkan kondisi perkembangan usaha penangkapan ikan oleh para pelaku usaha penangkapan pedesaan di sektor kelautan dan perikanan. Untuk mengetahui keragaan usaha penangkapan ikan pada lokasi penelitian menggunakan pendekatan metode analisis finansial (tanpa memperhatikan nilai uang karena faktor waktu) berupa costbenefit analysis, revenue-cost ratio (R/C) dan profitabilitas. Analisa Revenue Cost Ratio yaitu perbandingan atau imbangan antara total penerimaan dengan total biaya (Riyanto, 1995). Keuntungan usaha dihitung berdasarkan besarnya penerimaan setelah dikurangi dengan biaya yang dikeluarkan untuk proses produksi baik tetap maupun tidak tetap (Soekartawi,1993).

Mengacu pada Soekartawi (1993), penghitungan keuntungan dan efisiensi usaha menggunakan rumus :

$ת=\mathrm{TR}-\mathrm{TC}$

Total Cost (TC) dihitung melalui rumus :

$\mathrm{TC}=\mathrm{FC}+\mathrm{VC}$

Dimana

$$
\begin{aligned}
& л=\text { Keuntungan Usaha/ Profits } \\
& \text { TR }=\text { Total Penerimaan /Total Revenue } \\
& \text { TC }=\text { Total Biaya /Total Cost } \\
& \text { FC }=\text { Biaya Tetap /Fixed Costs } \\
& \text { VC }=\text { Biaya Variabel / Variable Costs }
\end{aligned}
$$

RC Ratio diperoleh melalui rumus :

$$
\mathrm{RC} \text { Ratio }=\frac{T R}{T C}
$$

\section{KARAKTERISTIK NELAYAN DAN MUSIM PENANGKAPAN}

Karakteristik responden ini sebagai data dasar untuk mengetahui kondisi sosial ekonomi rumah tangga perikanan dan kearah mana kebijakan perikanan tangkap dapat dikembangkan adalah seperti pada Tabel 1.

Secara ringkas tingkat pendidikan nelayan didominasi oleh tingkat pendidikan setara sekolah dasar khususnya untuk lokasi Sampang (100\%), Sibolga (62,5\%) dan Bitung (51\%). Jumlah tanggungan keluarga nelayan sebanyak 2-4 jiwa terbesar di Bitung (84 \%), Sampang (78\%) dan Sibolga (55\%). Untuk jumlah tanggungan $>5$ jiwa terdapat di Sibolga (45\%), Sampang (22\%) dan Bitung (16\%). 
Tabel 1. Karakteristik Responden Nelayan Skala Kecil di Kabupaten Sibolga, Sampang dan Bitung, 2011.

Table 1. Respondents Characteristics of Small Scale Fishers in the Distric of Sibolga, Sampang and Bitung, 2011.

\begin{tabular}{|c|c|c|c|c|}
\hline \multirow[b]{2}{*}{ No } & \multirow{2}{*}{$\begin{array}{l}\text { Karakteristik Responden/ } \\
\text { Respondents } \\
\text { Characteristics }\end{array}$} & \multicolumn{3}{|c|}{ Lokasi/ Location } \\
\hline & & $\begin{array}{l}\text { Sibolga } \\
(\%)\end{array}$ & $\begin{array}{c}\text { Sampang } \\
(\%)\end{array}$ & $\begin{array}{c}\text { Bitung } \\
(\%)\end{array}$ \\
\hline \multirow[t]{5}{*}{1} & Umur/Age & & & \\
\hline & $<25$ & 3 & 3 & 5 \\
\hline & $25-45$ & 40 & 45 & 73 \\
\hline & $46-64$ & 57 & 50 & 22 \\
\hline & $>65$ & 0 & 2 & 0 \\
\hline \multirow[t]{5}{*}{2} & $\begin{array}{l}\text { Tingkat Pendidikan/ } \\
\text { Education Levels }\end{array}$ & & & \\
\hline & SD/Elementary School & 62.5 & 100 & 51 \\
\hline & SLTP/Junior High School & 30 & 0 & 22 \\
\hline & SMA/ Senior High School & 7.5 & 0 & 24 \\
\hline & Perguruan Tinggi/ College & & & 3 \\
\hline \multirow[t]{3}{*}{3} & $\begin{array}{l}\text { Jumlah Anggota Keluarga } \\
\text { (Jiwa)/Numbers of } \\
\text { Family Members } \\
\text { (people) }\end{array}$ & & & \\
\hline & $2-4$ & 55 & 78 & 84 \\
\hline & $>5$ & 45 & 22 & 16 \\
\hline
\end{tabular}

Keterangan : Jumlah responden di Sibolga dan Sampang adalah 40 orang dan di Bitung adalah 37 orang. Note: Number of Respondents in Sibolga and Sampang is 40 people and Bitung is 37 people.

Sumber : Data primer, 2011/Source : Primary Data, 2011

Tabel 2. Sebaran Musim Penangkapan Ikan Menurut Bulan di Wilayah Sibolga, Sampang dan Bitung, 2011.

Table 2. Distribution of Fishing Season in The District of Sibolga , Sampang and Bitung, 2011.

\begin{tabular}{|c|c|c|c|}
\hline $\begin{array}{c}\text { Musim Penangkapan/ } \\
\text { Fishing Seasons }\end{array}$ & Sibolga & Sampang & Bitung \\
\hline Puncak/Harvest & $\begin{array}{l}\text { Januari - Juni/ } \\
\text { January - June }\end{array}$ & $\begin{array}{l}\text { Februari, April, Mei, } \\
\text { Oktober dan Desember } \\
\text { / February, April, May, } \\
\text { October and December }\end{array}$ & $\begin{array}{l}\text { Januari- Maret/ } \\
\text { January - March }\end{array}$ \\
\hline Peralihan/ Transitional & $\begin{array}{l}\text { Juli-Agustus/ } \\
\text { July-August }\end{array}$ & $\begin{array}{l}\text { Januari, Maret, Juni dan } \\
\text { Juli /January, March, } \\
\text { June, July }\end{array}$ & $\begin{array}{l}\text { April-Juni/ April } \\
\text { - June }\end{array}$ \\
\hline Paceklik/ Famine & $\begin{array}{l}\text { September- } \\
\text { Desember/ } \\
\text { September- } \\
\text { December }\end{array}$ & $\begin{array}{l}\text { September, Nopember } \\
\text { dan Desember / } \\
\text { September, November } \\
\text { and December }\end{array}$ & $\begin{array}{l}\text { Juli-Desember/ } \\
\text { July-December }\end{array}$ \\
\hline
\end{tabular}

Sumber : Data Primer Diolah, 2011./ Source : Primary Data Processed, 2011. 
Berdasarkan data tersebut menunjukkan bahwa keluarga nelayan di Sibolga merupakan keluarga besar, disusul di Sampang dan Bitung; hal ini sebagai pengaruh dari faktor sosial budaya dimana pada masyarakat Batak dan Madura umumnya berkumpul dalam satu keluarga menjadi suatu kebanggaan dan tanggungjawab terhadap keluarganya. Dengan diketahuinya karakteristik responden ini dapat dijadikan salah satu dasar pertimbangan penentuan target sasaran kemana arah dan strategi pengembangan kebijakan usaha penangkapan ikan di masa mendatang.

Usaha penangkapan ikan sangat dipengaruhi oleh faktor cuaca atau musim penangkapan. Musim penangkapan yang dikenal nelayan meliputi musim puncak, peralihan dan paceklik. Musim penangkapan ikan pada setiap daerah relatif berbeda baik dalam hal bulan maupun durasi musim penangkapan tersebut. Musim penangkapan pada beberapa lokasi penelitian dapat dilihat pada Tabel 2.

\section{DINAMIKA PENGUASAAN ASET, STRUKTUR BIAYA DAN PENERIMAAN USAHA}

Penguasaan aset mengalami kenaikan dari tahun 2010 ke 2011 (Tabel 3). Investasi usaha penangkapan ikan 2011 cukup bervariasi tergantung kepada jenis alat tangkap yang digunakan. Di Sibolga, investasi untuk penangkapan pelagis kecil rata-rata mencapai Rp.25.876.509,- per unitnya, dimana prosentase yang paling besar untuk pembelian kapal dan mesin yang mencapai $30,98 \%$ dan $24,81 \%$. Di Sampang, investasi penangkapan pelagis kecil mencapai Rp.46.068.944,- yang terdiri dari unit alat penangkapan jaring gillnet (jaring insang permukaan), payang, millenium (gillnet monofilamen); pada umumnya di Sampang mengoperasikan lebih satu alat tangkap yang dioperasikan sesuai dengan musimnya. Di Bitung, investasi penangkapan ikan pelagis besar dengan armada ukuran kapal < 5 GT sebesar Rp.55.631.271,-; sedangkan untuk ukuran kapal 5 - 30 GT sebesar Rp.211.248.673,-

Gambaran dinamika perkembangan usaha rumah tangga perikanan tangkap di laut dapat digambarkan seperti pada Tabel 4 dan 5, menunjukan adanya fluktuasi baik menurut musim penangkapan maupun tahun usaha; dari sisi biaya, biaya tidak tetap mengalami peningkatan $37 \%$ dan didominasi oleh pengeluaran untuk BBM.

Pada usaha penangkapan ikan pelagis kecil di Kota Sibolga pada tahun 2011 terjadi peningkatan biaya dibandingkan tahun

Tabel 3. Dinamika Penguasaan Aset dan Besarnya Biaya Investasi Berdasarkan Tipologi Penangkapan di lokasi Survei. 2010 -2011.

Table 3. Dynamics of Accumulated Assets and Value of Investment Cost According to Marine Fisheries Typology at Location Survey, 2010 -2011.

\begin{tabular}{|c|c|c|c|c|c|c|c|}
\hline \multirow[b]{2}{*}{ No } & \multirow{2}{*}{$\begin{array}{c}\text { Tipologi } \\
\text { Penangkapan/ } \\
\text { Captured } \\
\text { Fisheries } \\
\text { Typology }\end{array}$} & \multicolumn{2}{|c|}{ Sibolga } & \multicolumn{2}{|c|}{ Sampang } & \multicolumn{2}{|c|}{ Bitung } \\
\hline & & $\begin{array}{c}2010 \\
(R p)\end{array}$ & $\begin{array}{l}2011 \\
(R p)\end{array}$ & $\begin{array}{l}2010 \\
(R p)\end{array}$ & $\begin{array}{c}2011 \\
(R p)\end{array}$ & $\begin{array}{l}2010 \\
(R p)\end{array}$ & $\begin{array}{l}2011 \\
(R p)\end{array}$ \\
\hline 1 & $\begin{array}{l}\text { Pelagis Kecil/ } \\
\text { Small Pelagic }\end{array}$ & $19,985,231$ & $\begin{array}{r}25,876,509 \\
(29.47)\end{array}$ & $26,745,273$ & $\begin{array}{r}46,068,944 \\
(72.22)\end{array}$ & & \\
\hline 2 & $\begin{array}{l}\text { Pelagis Besar / } \\
\text { Large Pelagic } \\
\text { a. }<5 \mathrm{GT} / \text { Gross } \\
\text { Tonage } \\
\text { b. } 5-30 \mathrm{GT} / \\
\text { Gross Tonage }\end{array}$ & & & & & $\begin{array}{l}37,906,212 \\
99,259,859\end{array}$ & $\begin{array}{r}55,631,271 \\
(46.76) \\
211,248,673 \\
(112.82)\end{array}$ \\
\hline
\end{tabular}

Keterangan : Angka dalam kurung adalah persentase kenaikan/penurunan.

Note: Numbers in parentheses are the percentage increase /decrease.

Sumber : Data Primer, 2010, 2011./Source : Primary Data 2010, 2011 
sebelumnya, yaitu khususnya pada biaya tidak tetap (variable cost), meningkat sebanyak $7 \%$. Hal ini dikarenakan jumlah trip penangkapan pada tahun 2011 lebih banyak dibandingkan tahun 2010. Tentu saja hal ini berdampak pada peningkatan biaya operasional seperti bahan bakar dan perbekalan. Untuk usaha penangkapan ikan di lokasi Kabupaten Sampang dan Bitung, biaya usaha relatif mengalami penurunan. Hal tersebut dikarenakan oleh jumlah trip penangkapan yang berkurang juga dibandingkan tahun sebelumnya. Pengurangan trip yang dilakukan oleh nelayan di kedua lokasi tersebut disebabkan oleh beberapa hal, antara lain adalah terjadinya musim paceklik yang berkepanjangan (akibat angin barat maupun tidak ada ikan) dan juga keterbatasan modal nelayan untuk memenuhi kebutuhan operasional melaut.
Perkembangan usaha penangkapan ikan pelagis kecil di Kelurahan Aek Habil, Kabupaten Sibolga pada tahun 2011 mengalami peningkatan keuntungan sebesar $43 \%$ jika dibandingkan pada tahun 2010. Peningkatan biaya usaha pada usaha relatif berbanding lurus terhadap besarnya keuntungan yang diterimanya. Jika dilihat dari besarnya nilai $\mathrm{RC}$ ratio $(2,07)$, dapat disimpulkan bahwa usaha penangkapan ikan yang dilakukan oleh masyarakat masih layak dilakukan, karena nilai $\mathrm{RC}$ ratio $>1$. Pada Tabel 5 dapat dilihat bahwa usaha penangkapan ikan yang dilakukan sangat dinamis. Hal ini dibuktikan dengan adanya perbedaan atau fluktuasi baik biaya maupun penerimaan baik pada saat musim puncak, peralihan maupun paceklik, hal serupa dijumpai pula di Kelurahan Batu Lubang (Tabel 6 dan7).

Tabel 4. Dinamika Struktur Biaya Usaha Perikanan Tangkap di Lokasi Survei, 2010-2011.

Table 4. Dynamics of Costs Sructure at Fishing Operation at Location Survey, 2010 -2011.

\begin{tabular}{|c|c|c|c|c|c|c|}
\hline \multirow{2}{*}{ Uraian } & \multicolumn{2}{|c|}{ Sibolga } & \multicolumn{2}{|c|}{ Sampang } & \multicolumn{2}{|c|}{ Bitung } \\
\hline & 2010 & 2011 & 2010 & 2011 & 2010 & 2011 \\
\hline $\begin{array}{l}\text { Biaya Tetap (Rp/ } \\
\text { Thn)/ Fixed Costs } \\
\text { (Rp/year) }\end{array}$ & $\begin{array}{r}21,681,140 \\
(16)\end{array}$ & $\begin{array}{r}15,284,705 \\
(9)\end{array}$ & $\begin{array}{r}16,542,236 \\
(37)\end{array}$ & $\begin{array}{r}15,247,574 \\
(48)\end{array}$ & & \\
\hline$<5 \mathrm{GT}$ & & & & & $\begin{array}{r}13,750,700 \\
(14.23)\end{array}$ & $\begin{array}{r}13,894,967 \\
(14.29)\end{array}$ \\
\hline 5 - $30 \mathrm{GT}$ & & & & & $\begin{array}{r}21,736,827 \\
(17) \\
\end{array}$ & $\begin{array}{r}34,291,269 \\
(18) \\
\end{array}$ \\
\hline $\begin{array}{l}\text { Biaya Tidak Tetap } \\
\text { (Rp/Thn)/ Variable } \\
\text { Costs (Rp/year) }\end{array}$ & $\begin{array}{r}117,454,063 \\
(84)\end{array}$ & $\begin{array}{r}160,628,204 \\
(91)\end{array}$ & $\begin{array}{r}28,437,333 \\
(63)\end{array}$ & $\begin{array}{r}16,160,200 \\
(52\end{array}$ & & \\
\hline$<5 \mathrm{GT}$ & & & & & $\begin{array}{r}82,856,526 \\
(85.77)\end{array}$ & $\begin{array}{r}83,332,624 \\
(85.71)\end{array}$ \\
\hline 5 - 30 GT & & & & & $108,875,635$ & $151,858,396$ \\
\hline & & & & & (83) & (82) \\
\hline $\begin{array}{l}\text { Total Biaya }(\mathrm{Rp} / \mathrm{Thn}) / \\
\text { Total Cost }\end{array}$ & $\begin{array}{r}139,135,203 \\
(100)\end{array}$ & $\begin{array}{r}175,912,909 \\
(100)\end{array}$ & $\begin{array}{r}44,979,569 \\
(100)\end{array}$ & $\begin{array}{r}31,407,774 \\
(100)\end{array}$ & & \\
\hline$<5 \mathrm{GT}$ & & & & & $\begin{array}{r}96,607,226 \\
(100)\end{array}$ & $\begin{array}{r}97,227,591 \\
(100)\end{array}$ \\
\hline 5 - $30 \mathrm{GT}$ & & & & & $\begin{array}{r}130,612,462 \\
(100)\end{array}$ & $\begin{array}{r}186,149,665 \\
(100)\end{array}$ \\
\hline
\end{tabular}

Keterangan : Angka dalam kurung adalah persentase/Note: Numbers in parentheses are the percentage Sumber : Data Primer, 2010, 2011/Source : Primary data, 2010, 2011. 


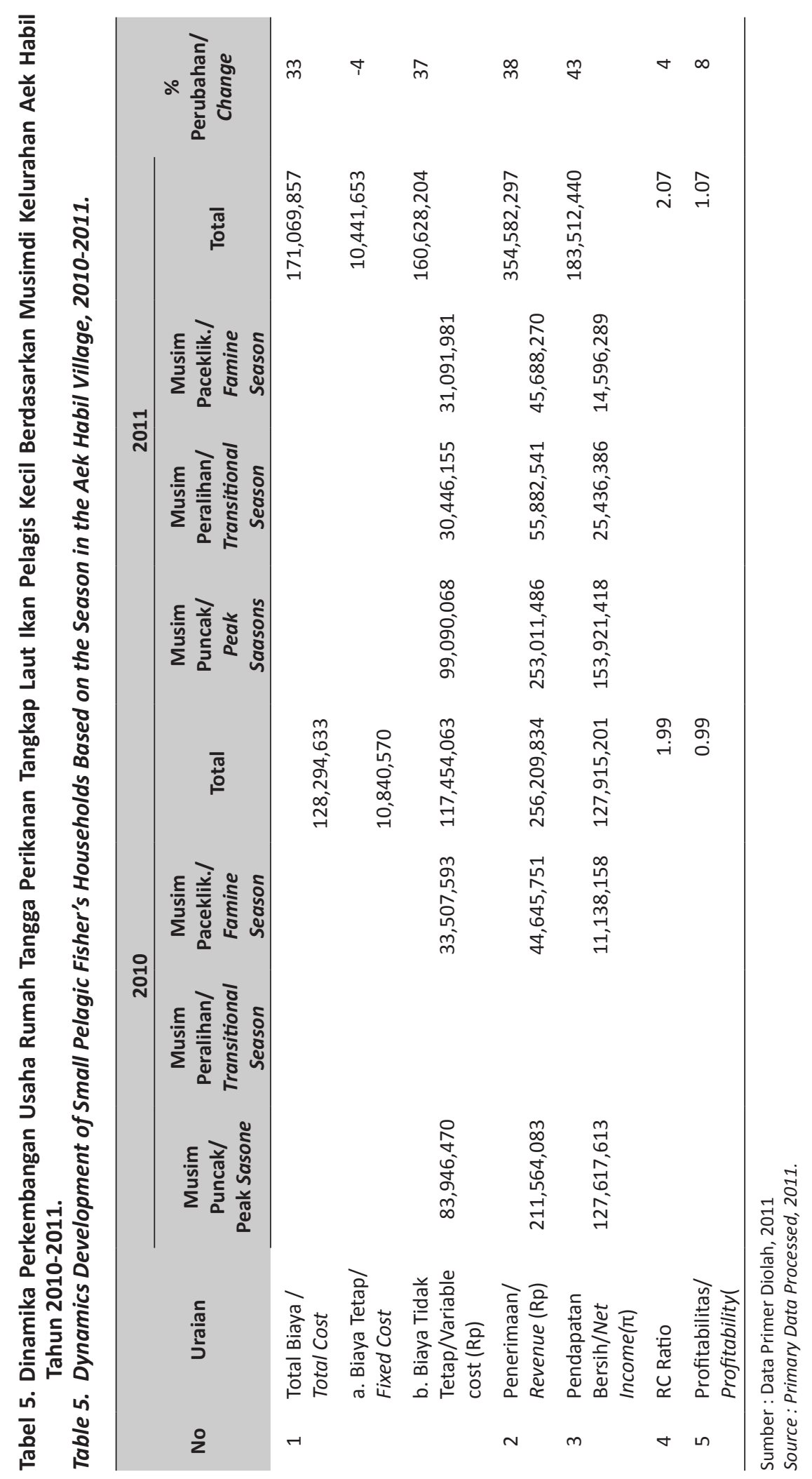




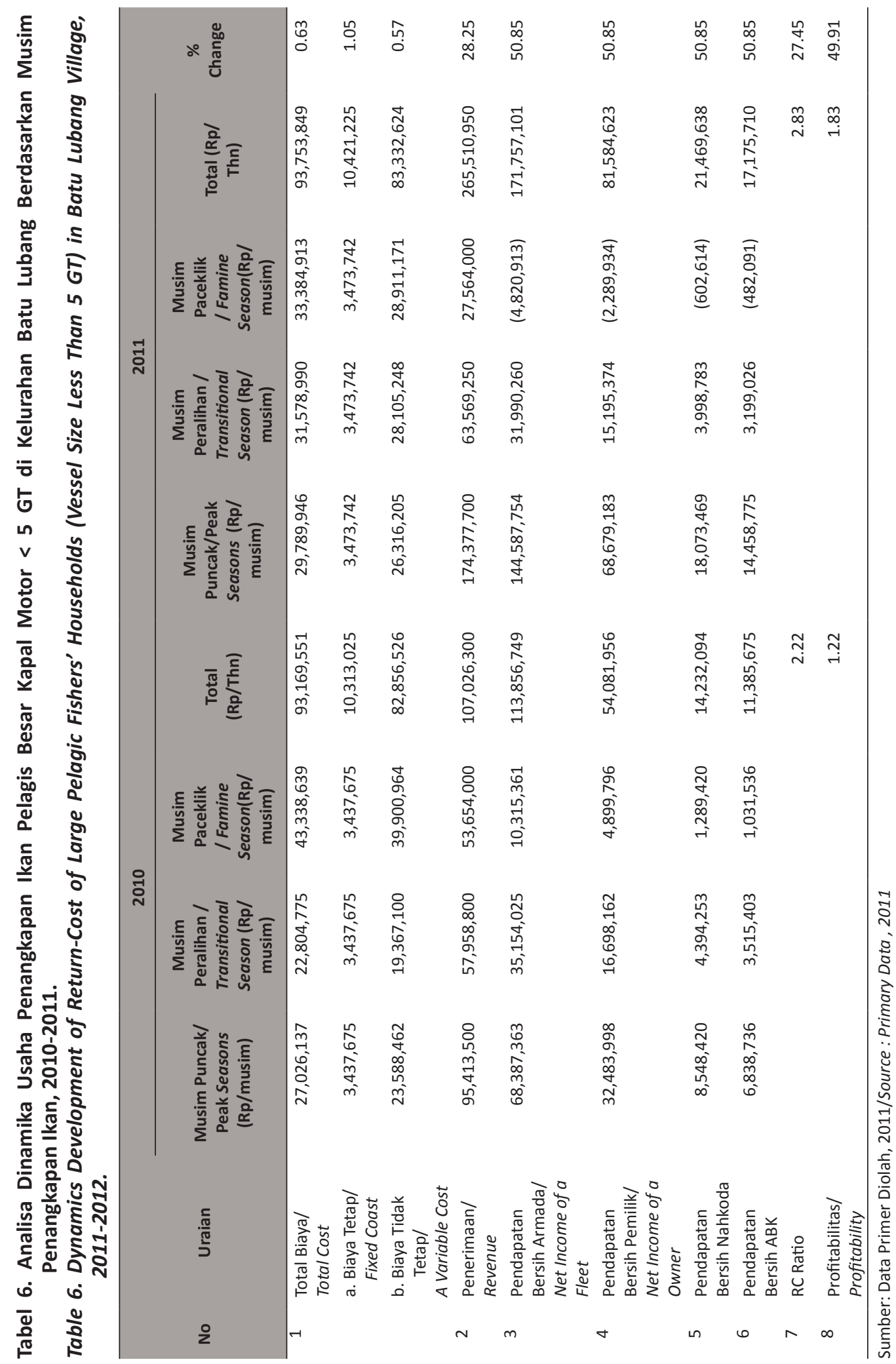




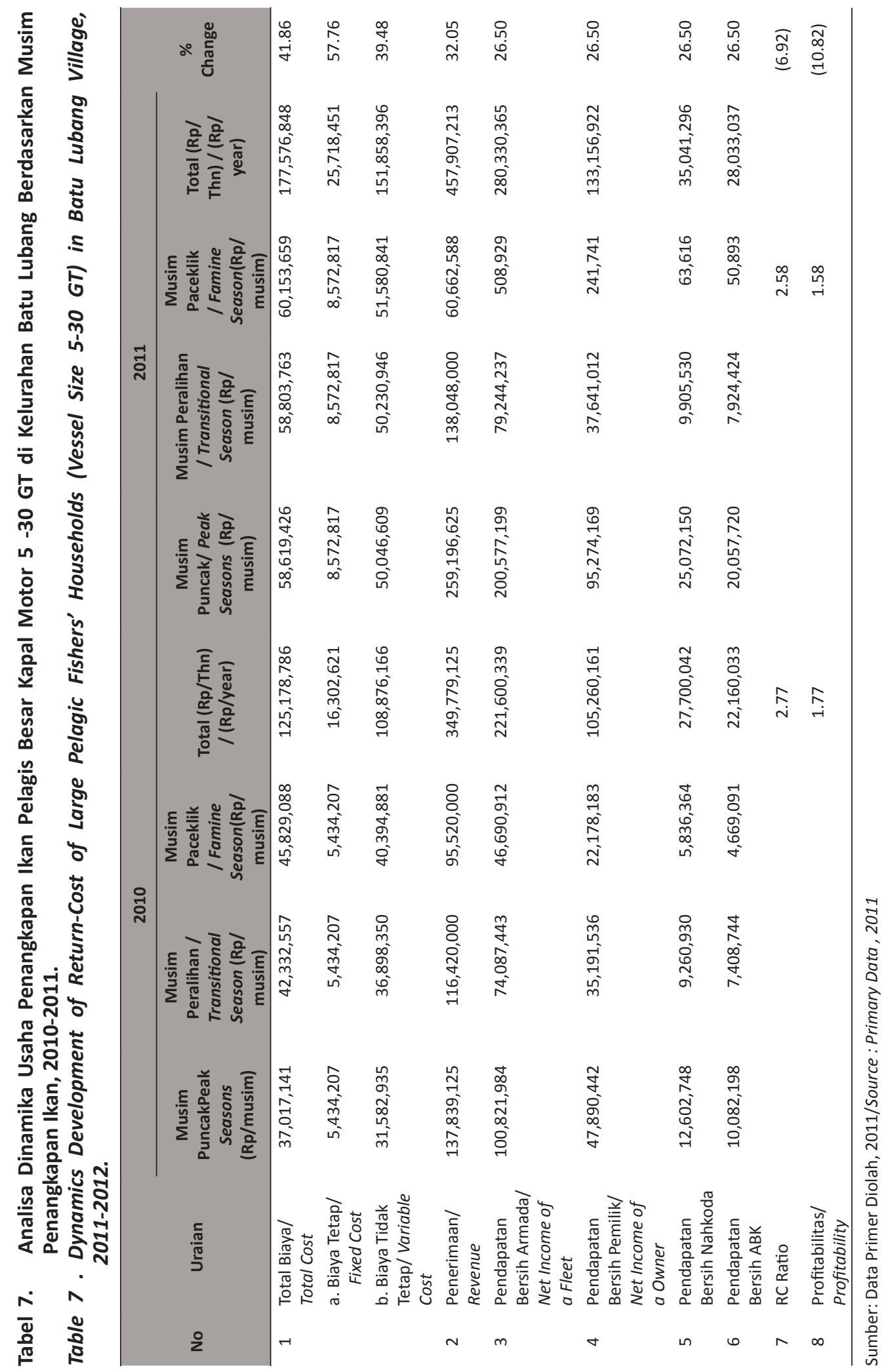


Pada usaha penangkapan ikan pelagis besar di Kelurahan Batu Lubang pada tahun 2011 terjadi peningkatan biaya dibandingkan tahun sebelumnya baik pada usaha penangkapan dengan menggunakan armada berukuran kurang dari 5 GT maupun 5-30 GT. Khususnya pada biaya tidak tetap (variable cost), meningkat sebanyak $0.57 \%$ pada usaha penangkapan dengan armada 5 GT dan $39,48 \%$ pada armada 5-30 GT.

\section{URGENSI FASILITAS PETA PRAKIRAAN "FISHING GROUND"}

Dalam melakukan usaha penangkapan ikan di laut, nelayan hanya berpedoman pada kebiasaan turun-temurun yang secara tradisional telah berlangsung, yakni dengan memperhatikan tanda-tanda alam yang ada; padahal selama lima tahun terakhir telah terjadi pergeseran musim penangkapan serta lokasi penangkapan ikan yang semakin menjauh dari daratan. Di lain pihak, hasil kajian Kajian Nasional Pengkajian Jenis dan Stok Ikan (KOMNAS KAJISKAN) memperlihatkan bahwa ketersediaaan sumberdaya ikan di daerah penangkapan yang biasa mereka kunjungi telah menurun sampai tingkat 'over-fishing'; sehingga mereka terpaksa harus menempuh jarak dan waktu yang relatif lama untuk mencari keberadaan ikan atau daerah penangkapan ikan (fishing ground). Hal ini berdampak pada peningkatan biaya operasional yang harus dikeluarkan, terutama untuk pembelian BBM.

Sejak tahun 2000, telah dilakukan upaya untuk membantu aktivitas penangkapan ikan yang dilakukan oleh nelayan terutama dalam hal penghematan BBM yaitu melalui pembuatan Peta Prakiraan Daerah Penangkapan Ikan (Peta Fishing Ground) yang di rintis oleh Balai Penelitian dan Observasi Laut. Sebagai contoh, pada Gambar 1 dan 2 dapat dilihat peta prakiraan penangkapan ikan di wilayah jawa, bali dan nusa tenggara yang dirilis oleh Balai Penelitian dan Observasi Laut, Balitbang
KP, KKP . Pada gambar tersebut diketahui bahwa dalam rentang waktu satu bulan (bulan Mei s/d Juni 2012) telah terjadi pergeseran lokasi penangkapan ikan serta lokasi yang memiliki potensi ikan. Diketahui bahwa pada Bulan Mei, daerah penangkapan ikan berada di sekitar perairan Jawa Timur dan Perairan Selatan dan Utara Pulau Bali (Gambar 1). Pada Bulan Juni, daerah penangkapan ikan bergeser menjadi di sekitar Perairan Bagian Barat Pulau Jawa atau Selat Sunda.

Peta prakiraan fishing ground yang dibuat oleh Balai Penelitian dan Observasi Laut, Badan Penelitian dan Pengembangan Kelautan dan Perikanan (Balitbang KP), Kementerian Kelautan dan Perikanan (KKP) diterbitkan hampir setiap hari dan dapat diakses secara gratis melalui situs Kementerian Kelautan dan Perikanan (KKP, 2012). Namun kenyataannya, walaupun dapat diakses secara gratis tidak banyak nelayan yang mengetahui informasi tersebut, terlebih nelayan tradisional yang memiliki banyak keterbatasan dalam hal pengoperasian teknologi informasi serta akses terhadapnya.

Didalam peta prakiraan fishing ground ini terkandung informasi mengenai koordinat lintang- bujur daerah yang diduga sebagai daerah penangkapan ikan dan daerah yang diduga berpotensi sebagai daerah penangkapan ikan. Sejauh ini, peta tersebut baru didistribusikan ke pelabuhan-pelabuhan perikanan besar (PPS dan PPN). Peta tersebut diakui bermanfaat (Anonim, 2008) tetapi sampai saat ini belum dapat dinikmati oleh nelayan skala kecil. Oleh karena itu, untuk meningkatkan efektivitas dan efisiensi kegiatan penangkapan ikan skala kecil direkomendasikan untuk mendistribusikan dan mensosialisasikan peta prakiraan fishing ground tersebut hingga ke tingkat nelayan kecil. Tentu saja disertai dengan tata cara penerjemahan peta tersebut sehingga dapat diaplikasikan dengan mudah oleh nelayan.

Dengan dibekali peta prakiraan fishing ground diharapkan nelayan dapat lebih efektif (lebih cepat) mencapai 


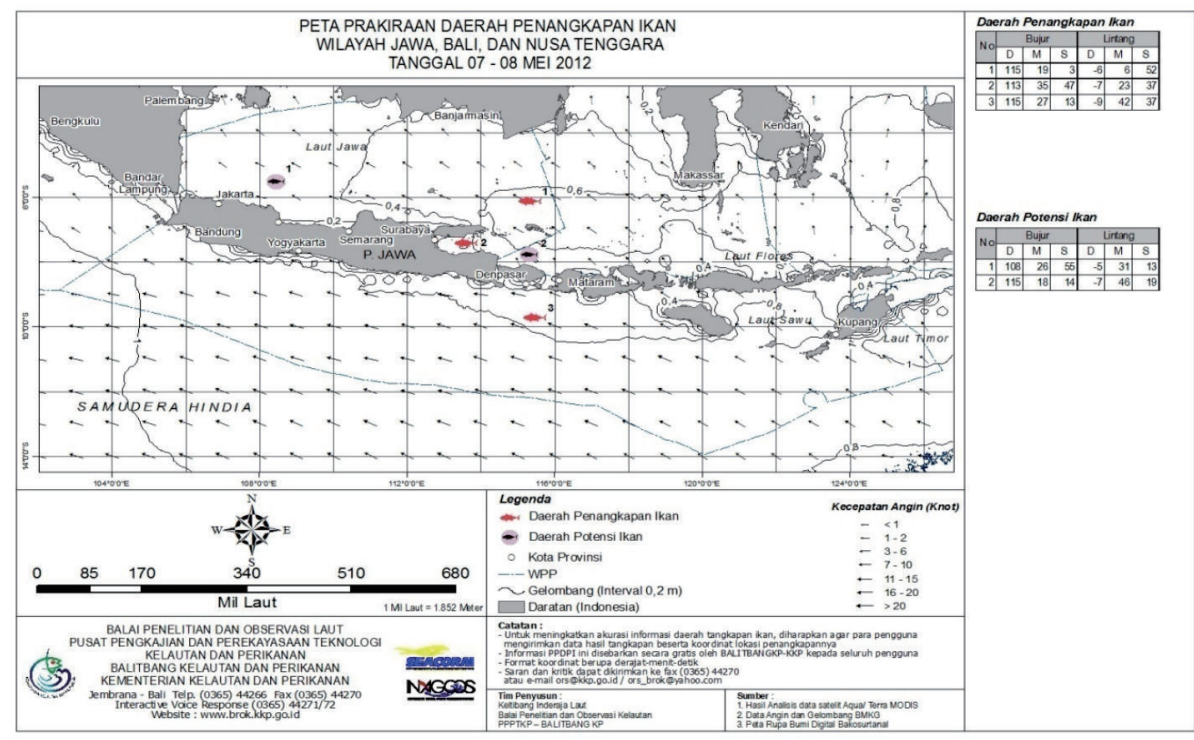

Gambar 1. Peta Prakiraan Penangkapan Ikan Wilayah Jawa, Bali dan Nusa Tenggara Tanggal 7-8 Mei 2012.

Figure 1. Fishing Ground Forecast Map of Java, Bali and Nusa Tenggara 7 - 8 May 2012.

Sumber : Kementerian Kelautan dan Perikanan (2012)

Source : Ministry of Marine Affairs and Fisheries Reupblic of Indonesia(2012)

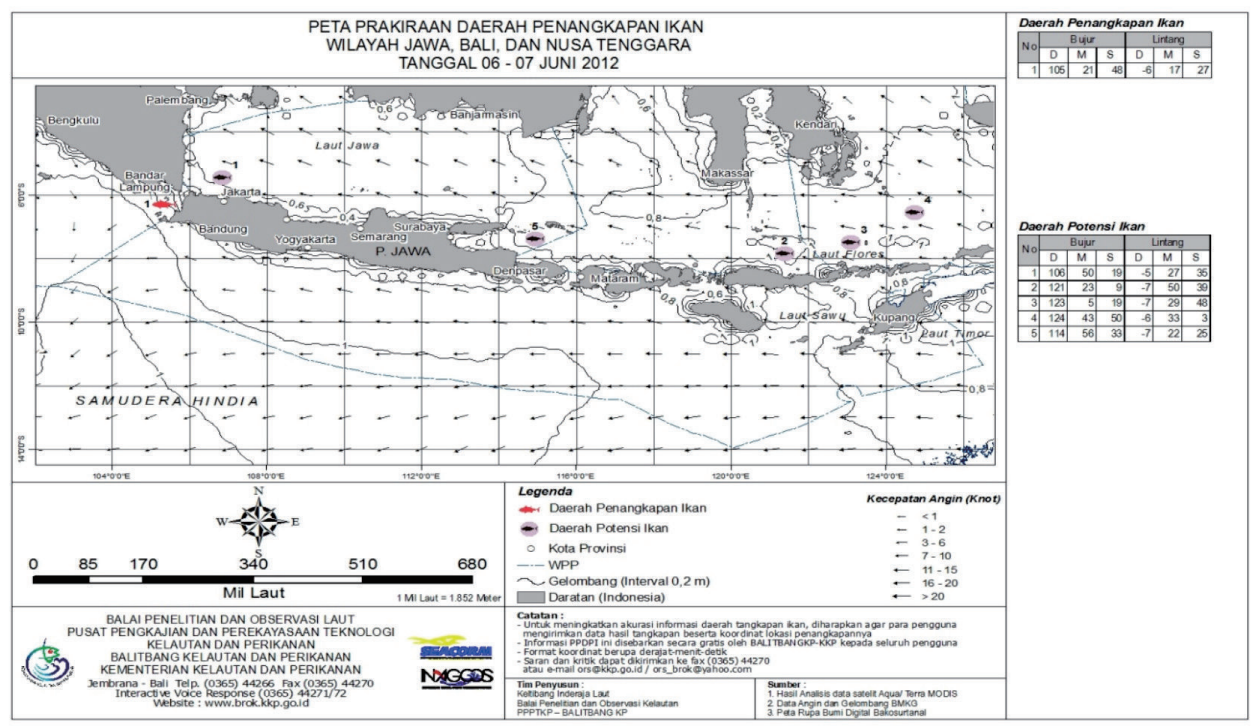

Gambar 2. Peta Prakiraan Daerah Penangkapan Ikan Wilayah Jawa, Bali dan Nusa Tenggara Tanggal 6 - 7 Juni 2012.

Figure 2. Fishing Ground Forecast Map of Java, Bali and Nusa Tenggara 6 - 7 June 2012.

Sumber : Kementerian Kelautan dan Perikanan (2012)

Source : Ministry of Marine Affairs and Fisheries Reupblic of Indonesia (2012) 
daerah penangkapan ikan dan efisien (lebih hemat) dalam memanfaatkan ketersediaan BBM yang dimiliki. Pada akhirnya diharapkan melalui upaya ini biaya operasional dapat ditekan dan pendapatan nelayan mengalami peningkatan. Bila efisiensi waktu penangkapan dapat terjadi diharapkan nelayan mempunyai kesempatan untuk mengalokasikan waktu yang dimiliki untuk melakukan aktivitas ekonomi lainnya sehingga peningkatan kesejahteraan rumah tangga nelayan diharapkan dapat meningkat.

\section{PENUTUP}

Kebijakan fasilitasi Peta Perkiraan 'Fishing Ground' dapat dilakukan melalui tahapan perencanaan, pengaturan, implementasi dan monitoring serta evaluasi di tingkat pusat (Direktorat Jenderal Perikanan Tangkap) dan tingkat lokal, baik Dinas Kelautan dan Perikanan Propinsi maupun Kabupaten/Kota. Selanjutnya, melalui institusi tersebut diatas, peta prakiraan fishing ground yang di produksi oleh BPOL dapat di perbanyak dan didistribusikan sampai ke tangan nelayan skala kecil melalui mekanisme formal maupun non formal dinas terkait ke pelabuhan pendaratan ikan dan/ atau ke kelompok-kelompok nelayan maupun kelompok usaha bersama yang telah terbentuk. Pada tahap perencanaan dan penganggaran, politik keberpihakan pada kelompok usaha skala kecil harus menjadi 'mainstream' baik di tingkat pusat maupun daerah; pengaturan lebih lanjut perlu diuraian secara lebih terinci sehingga kebijakan tersebut mampu mencapai target sasaran yang diinginkan. Dalam hal monitoring dan evaluasi kinerja implementasi, perlu dilakukan kerjasama yang lebih intensif baik direktorat teknis, unit teknis pengembangan KP di tingkat lokal, lembaga penelitian maupun penyuluh lapang. Secara keseluruhan, model pengelolaan harus di arahkan ke model pengelolaan perikanan secara bersama bersifat adaptif.

\section{DAFTAR PUSTAKA}

Anonim.2008. Peta Prakiraan Daerah Penangkapan Ikan (PPDPI) da Distribusinya. (http://www.brok.kkp.go.id/news/5/ Peta-Prakiraan-Daerah-PenangkapanIkan-(PPDPI)-Dan-Distribusinya, diakses pada tanggal 18 Januari 2012).

.2012. Peta Prakiraan Daearah Penangkapan Ikan Wilayah Jawa, Bali dan Nusa Tenggara. (http://www.kkp. go.id, diakses pada tanggal 20 Juni 2012.

Bahri, R. 1995. Pembangunan dan Strategi Memerangi Kemiskinan. Liberty. Yogyakarta.

Dahuri, R. 2003. Pendayagunaan Sumberdaya Kelautan Untuk Kesejahteraan Rakyat. Lembaga Informasi dan Studi Pembangunan Indonesia (LISPI). Jakarta.

Dwiponggo, A., C. Bailey dan F. Maharudin. 1988. The Indonesian Marine Fisheries, Structure and Change. ICLARM, DGF, IRMF. Jakarta.

Riyanto, N. 1995. Dasar-Dasar Pembelanjaan Perusahaan. Gajahmada. Yogyakarta.

Soekartawi. 1993. Agribisnis Teori dan Aplikasinya. Rajawali Press. Jakarta.

Wijaya, R.A., S. Koeshendrajana dan A. Azizi. 2010. Perkembangan Usaha Penangkapan Ikan Pelagis Besar di Desa Batu Lubang, Bitung, Sulawesi Utara. PANELKANAS : Upaya Pemantauan Indikator Kinerja Mikro Pembangunan Kelautan dan Perikanan hal 107 s/d130. Balai Besar Penelitian Sosial Ekonomi Kelautan dan Perikanan. Badan Penelitian dan Pengembangan Kelautan dan Perikanan. Kementerian Kelautan dan Perikanan. Jakarta. 